\title{
Modeling of Irrigation Process Using Fuzzy Logic for Combating Drought
}

\author{
${ }^{* 1}$ M. Fatih ADAK \\ ${ }^{1 *}$ Faculty of Computer and Information Sciences, Department of Computer Engineering, Sakarya University, Turkey
}

\begin{abstract}
The increased popularity of smart home technologies, lower prices of technical infrastructure and the growing demand for these technologies accelerated the development of smart systems. Automatic irrigation of the soil with the help of automatic systems will prevent sufficient irrigation of the soil in dry periods. This can cause the cultivated area and garden plants wither and eventually die. In this study, a smart plant irrigation system is developed, aiming to address the need for these systems in such cases. The system here is created using various sensors, and, through application of a fuzzy model, it can determine the amount of water required for a specific period. The fuzzy model determines the exact amount of water needed by the plant, hence prevents undesirable situations like excessive or insufficient watering of the plant. This enables planning for soil irrigation. The system proposed in this paper is a low-cost and easy-to-install one that can be applied in any agriculture.
\end{abstract}

Key words: fuzzy logic, drought, irrigation

\section{Introduction}

Concepts such as smart homes and Industry 4.0 involve studies about facilitating human life. Remote control of home appliances, and air quality analysis can be given as common examples of these studies. Plant watering is another possible application area of smart technologies. House and garden plants need regular watering. But the required amount of water and the watering interval may change for each plant. Plants in pots and garden plants that are left alone for a long time are required to be watered regularly in that period. Today irregularity of rainfall has led to the planning of the irrigation process. Irrigation planning is of great importance for dry periods, besides ensuring that water is not wasted. This water saving has a vital importance, since 70\% of the Earth's water consumption is accounted for agricultural use [1]. On the other hand these type of studies improve the economic feasibility. Compana et al approved this idea and they give improvement as a decrease of $18.8 \%$ in the investment capital cost [2]. In this study, sensor data is supplied as an input to the proposed fuzzy model to determine the irrigation process. There are similar irrigation models in the literature such as controlling the need for irrigation in agricultural sector, especially in greenhouses [3-6]. There are some studies use automatic irrigation systems that don't have remote control units [7]. Which needs to be present near the system. Cakir et al has developed an automatic irrigation system over the phone line [8].

However, they only consider the sensor information about soil moisture. In another study on

\footnotetext{
${ }^{*}$ Corresponding author: Address: Address: Faculty of Computer and Information Sciences, Department of Computer Engineering, Sakarya University, 54187, Sakarya TURKEY. E-mail address: fatihadak@ sakarya.edu.tr
} 
greenhouses, many parameters such as temperature, air and soil moisture were taken into consideration [9]. Similar to our work here, fuzzy modeling has also been applied successfully using air and soil moisture and temperature sensors [10]. Successful results were obtained using soil moisture sensor together with Arduino in agricultural irrigation [11]. In another study where machine learning and ANFIS were used, again three basic sensors were included [12]. There are studies that use pure artificial neural networks (ANN). For example Muhammad et al developed a controller and compared by on/of controllers, they said ANN based approach has good performance when compared to on/off controllers [13]. Another study developed a new matrix system using soil moisture and temperature sensors for automatic irrigation [14]. The information of humidity and temperature of the air can be obtained relatively easily, while getting soil moisture information is a troublesome process [15]. Because, the sensor that is sunk in a certain place of the soil will gather the information about only that part of the soil. Therefore, the sensor should be placed in the most suitable side of the pot or garden soil. As it is evident from the aforementioned studies, smart irrigation systems are among popular research topics today and will maintain its popularity in the near future. This study consists of 5 sections. In Section 2, Fuzzy Logic and the data are explained. The proposed model is explained in Section 3, the results are presented in Section 4, and conclusive remarks are given in the last Section.

\section{Materials and Method}

\subsection{Fuzzy Logic}

In contrast to the crisp approach of full membership, the fuzzy set approach permits partial membership and is successfully applied to real life problems. Fuzzy logic consists of input, membership functions, fuzzification, fuzzy rules and defuzzification stages [16]. The fuzzy set theory is given in Eq. 1. $\tilde{\mathrm{A}}$ is the fuzzy set, $\mathrm{x}$ is the finite universal set and $\mu_{\tilde{\AA}}(\mathrm{x})$ is the membership function in Eq. 1. In some real life problems it is hard to write rules for fuzzy model and often researchers use statistic and data mining techniques [17-18]. But in this study, it wasn't difficult to write rules for irrigation fuzzy model because of models basic nature and based on heuristic manner.

$$
\begin{aligned}
& \tilde{\mathrm{A}}=\left\{\left(\mathrm{x}, \mu_{\tilde{\mathrm{A}}}(\mathrm{x})\right) \forall \mathrm{x} \in \mathrm{X}\right\} \\
& \mu_{\tilde{\mathrm{A}}}(\mathrm{x}): \mathrm{X} \rightarrow[0,1]
\end{aligned}
$$

\subsection{JFuzzyLogic}

The model in this study is coded in Java, and the fuzzy logic library JfuzzyLogic is used. JfuzzyLogic is an extensive library developed by Cingolani Alcala - Fdez, which can be run in any environment and supports many more membership functions than other equivalent libraries [19]. This free library increases the amount of researchers implementing fuzzy logic controllers. It is now just support Mamdani but not Sugeno model.

\section{Results}


Model developed using Mamdani has four inputs and one output. The inputs are soil moisture, rainfall probability, air humidity and temperature. The output is liter. In this model the most suitable irrigation amount is calculated in terms of combating drought. Membership functions used in inputs are given in Fig. 1. As shown in Fig. 1 each input has 3 membership functions. Soil moisture, air humidity and temperature values are taken from related sensors. Rainfall probability is taken from Turkish State Meteorological web service. Soil moisture has three forms dry, damp and wet. Air humidity has three forms, dry, damp and muggy. Temperature has three forms, low, high and middler. The last input rainfall probability has also three forms and those are calculated by next three day rainfall probability as shown in Fig. 2.
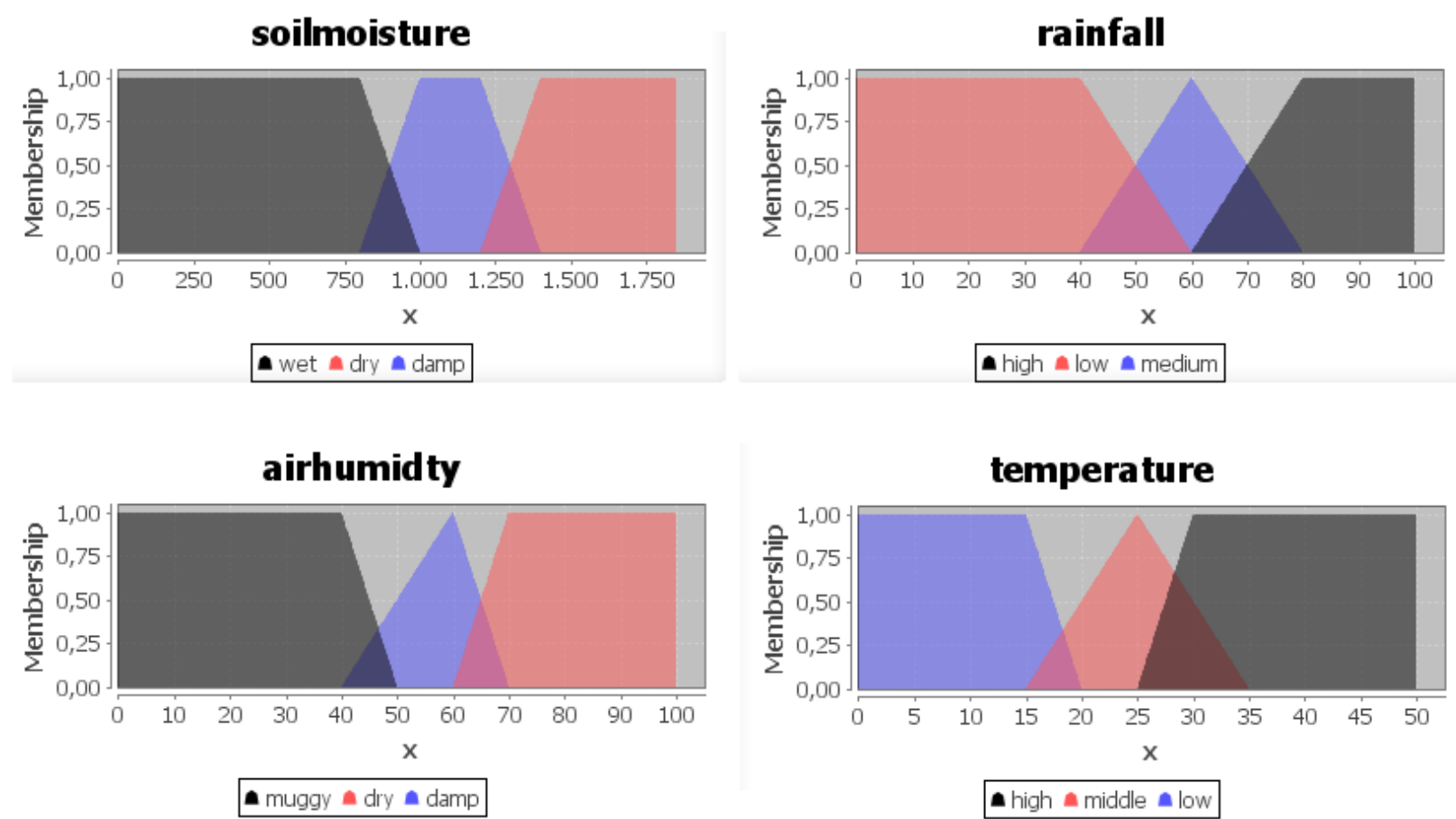

Figure 1. Membership functions of fuzzy inputs

Cities \& Holiday Resorts | ADAPAZARI
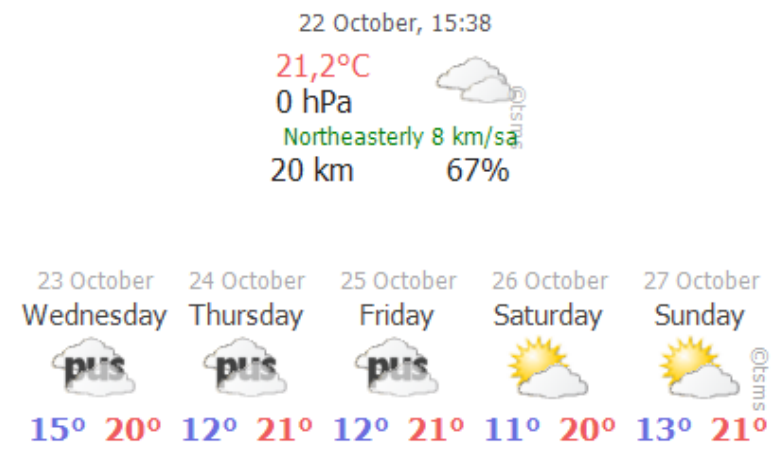

Figure 2. The input rainfall information

As seen in Fig. 1, generally trapezoid and triangle membership functions are used in the model. 
Center of gravity method is used for defuzzification method. For AND method min is used, for activation also min is used and for accumulation method max is used. The mode gives crisp output in liter per day and if the output is smaller than 20 liters the system won't give any water. The membership functions for output is given in Fig. 3.

liter

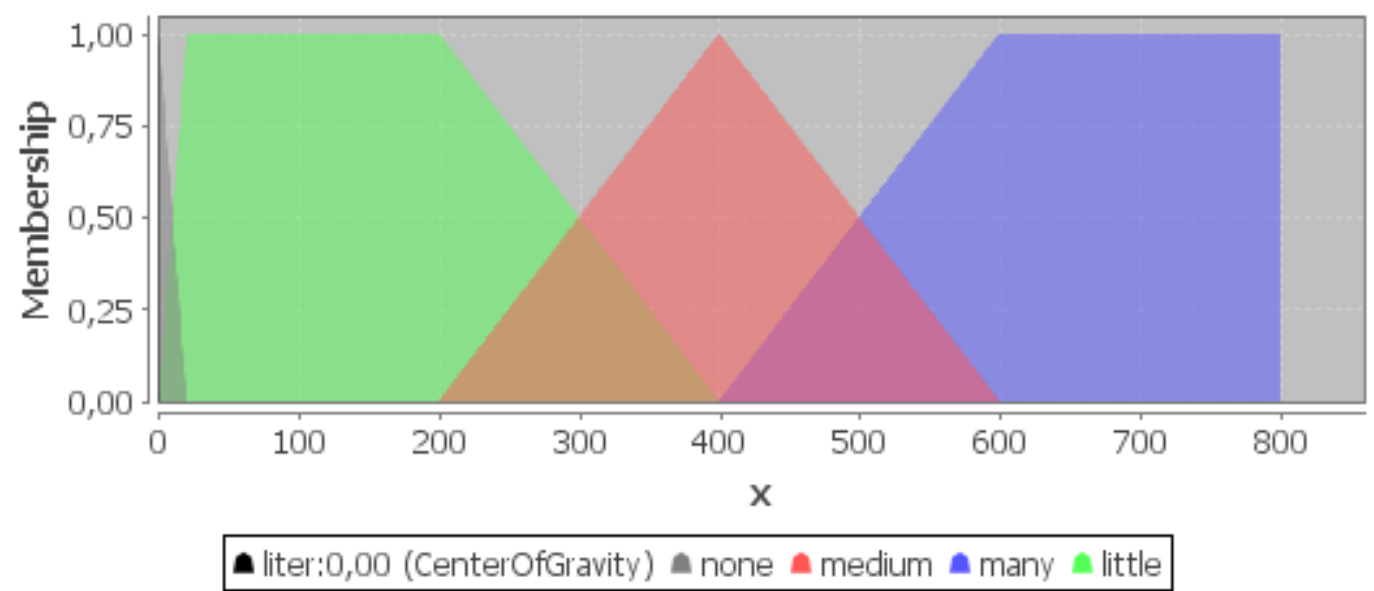

Figure 3. Membership functions of fuzzy output

In fuzzy model 81 fuzzy rules are used. All rules have one for width value. The model developed in this study was tested on a real garden. A reservoir close to one tone was optimally organized with the help of the fuzzy model in this study. During the week, irrigation was realized economically.

\section{Conclusions}

In terms of combating drought, systems that can be installed cheap are of great importance today. Therefore, the model developed in this study is cheap and irrigation planning is an important result of the study. Irrigation planning is modelled by looking at temperature, air and moisture in the soil, and most importantly the probability of rainfall for the next few days. In the case study irrigation was performed successfully with the help of fuzzy model. As a future study, it is planned to develop a more dynamic and complex irrigation model by adding parameters such as soil minerals and water requirement of the plant.

\section{References}

[1] S. Kang, X. Hao, T. Du, L. Tong, X. Su, H. Lu, X. Li, Z. Huo, S. Li, and R. Ding, "Improving agricultural water productivity to ensure food security in China under changing environment: From research to practice," Agric. Water Manag., vol. 179, pp. 5-17, Jan. 2017.

[2] P. E. Campana, H. Li, J. Zhang, R. Zhang, J. Liu, and J. Yan, "Economic optimization of photovoltaic water pumping systems for irrigation" Energy Convers. Manag., vol. 95, pp. 32 -41, May 2015.

[3] M. Azaza, C. Tanougast, E. Fabrizio, and A. Mami, "Smart greenhouse fuzzy logic based control system enhanced with wireless data monitoring" ISA Trans., vol. 61, pp. 297 - 307, Mar. 2016.

[4] S. Yongxian, W. Jingzhuo, and Z. Xianjin, "Greenhouse Environment Parameters Optimization and Wireless Monitoring Based on Maximize Profit Margin" Sens. Lett., vol. 14, no. 11, pp. 1129 - 1137, Nov. 2016. 
[5] J.A. Jiang, C.H. Wang, M.S. Liao, X.Y. Zheng, J.H. Liu, C.L. Chuang, C.L. Hung, and C.P. Chen, "A wireless sensor network - based monitoring system with dynamic convergecast tree algorithm for precision cultivation management in orchid greenhouses" Precis. Agric., vol. 17, no. 6, pp. 766 - 785, Dec. 2016.

[6] G. Nicolosi, R. Volpe, and A. Messineo, "An Innovative Adaptive Control System to Regulate Microclimatic Conditions in a Greenhouse" Energies, vol. 10, no. 5, p. 722, May 2017.

[7] A. R. Al-Ali, S. Rehman, S. Al-Agili, M. H. Al-Omari, and M. Al-Fayezi, "Usage of photovoltaics in an automated irrigation system" Renew. Energy, vol. 23, no. 1, pp. 17 - 26, May 2001.

[8] A. Cakir and H. Calis, "Uzaktan Kontrollu Otomatik Sulama Sistemi Tasarimi ve Uygulamasi" Suleyman Demirel Universitesi Fen Bilim. Enstitusu Derg., vol. 11, no. 3, 2007.

[9] A. Yilmaz, "Sera ici Hava Sartlarinin Otomasyon Sistemi ile Uretim Kalitesinin Artirilmasi ile ilgili Bir Calisma" J. Life Sci., vol. 622, no. 2, pp. 145 - 159, 2016.

[10] C. R. Algarin, J. C. Cabarcas, and A. P. Llanos, "Low-Cost Fuzzy Logic Control for Greenhouse Environments with Web Monitoring" Electronics, vol. 6, no. 4, p. 71, Sep. 2017.

[11] P. Jain, P. Kumar, and D. K. Palwalia, "Irrigation management system with micro-controller application" in 2017 1st International Conference on Electronics, Materials Engineering and Nano-Technology (IEMENTech), 2017, pp. 1 - 6.

[12] M. N. Rajkumar, S. Abinaya, and V. V. Kumar, "Intelligent irrigation system ? An IOT based approach" in 2017 International Conference on Innovations in Green Energy and Healthcare Technologies (IGEHT), 2017, pp. 1 - 5.

[13] Umair, S. Muhammad, and R. Usman. "Automation of irrigation system using ANN based controller" International Journal of Electrical and Computer Sciences IJECS-IJENS 10.02 (2010): 41-47.

[14] P. Sengottuvel and J. Hameed Hussain, "Design and implementation of automatic plant irrigation system" Int. J. Pure Appl. Math., vol. 119, no. Special Issue 7C, pp. 2031 - 2036, 2018.

[15] I. Schröter, H. Paasche, D. Doktor, X. Xu, P. Dietrich, and U. Wollschläger, "Estimating Soil Moisture Patterns with Remote Sensing and Terrain Data at the Small Catchment Scale" Vadose Zo. J., vol. 16, no. 10, p. 0, 2017.

[16] L. A. Zadeh, "Fuzzy sets" Inf. Control, vol. 8, no. 3, pp. 338 - 353, Jun. 1965.

[17] M. F. Adak, N. Yumusak, and H. Taskin, "An elective course suggestion system developed in computer engineering department using fuzzy logic" in 2016 International Conference on Industrial Informatics and Computer Systems (CIICS), 2016, pp. 1 - 5.

[18] M. F. Adak, "Software defect detection by using data mining based fuzzy logic" in 2018 Sixth International Conference on Digital Information, Networking, and Wireless Communications (DINWC), 2018, pp. 65 - 69.

[19] P. Cingolani and J. Alcala \$-\$Fdez, "jFuzzyLogic: a Java Library to Design Fuzzy Logic Controllers According to the Standard for Fuzzy Control Programming" Int. J. Comput. Intell. Syst., vol. 6, no. sup1, pp. 61\$ - \$75, Jun. 2013. 